This paper is published in the open archive of Mid Sweden University

DIVA http://miun.diva-portal.org

with permission of the publisher

Citation for the peer-reviewed published paper:

Sjöberg J, Häggquist $M$, Wikström $M$, Lindström $T$, Höglund $H$. Effects of pressurised high consistency refining on sheet density. ; Nordic Pulp \& Paper Research Journal. 2008;23(1):39-45.

URL to article at publishers site:

http://dx.doi.org/10.3183/NPPRJ-2008-23-01-p039-045 


\section{Effects of pressurised high consistency refining on sheet density}

Jessica C. Sjöberg, Mid Sweden University, Sundsvall, Mats Häggquist, Korsnäs AB, Sweden, Magnus Wikström, Billerud AB, Sweden, Tom Lindström,.STFI-Packforsk AB, Sweden, Hans Höglund, Mid Sweden University, Sundsvall

KEYWORDS: Density, Fibre length, Hornification, Plug screw, Pressurised HC refining, Shape factor

SUMMARY: This study investigates the possibility of decreasing the sheet density of paper made from unbleached kraft pulp for the middle layer in board production. The objective was to evaluate how treatments in a compressive screw equipment pressure expansion (PREX) plug screw feeder, atmospheric $\left(\mathrm{HC}_{\text {atm }}\right)$ and pressurised high-consistency refining $\left(\mathrm{HC}_{\text {press }}\right.$ refining) affect both fibre and paper properties and, in particular, how fibre curl affects sheet density.

The plug screw pre-treatments and $\mathrm{HC}$ refining were performed under atmospheric and steam-pressurised conditions at $100^{\circ} \mathrm{C}, 125^{\circ} \mathrm{C}$ and $175^{\circ} \mathrm{C}$. Even though fibre curl increased considerably during plug screw treatment and $\mathrm{HC}_{\text {atm }}$ and $\mathrm{HC}_{\text {press }}$ refining, the density of the paper sheets did not decrease, as had been expected. A possible explanation for this result may be that the fibres become more flexible during curl treatment, resulting in increased sheet density.

In order to obtain fibres that were both very curly and stiff, three ways of improving the fibre stiffness were tested: 1) lowering the $\mathrm{pH}$ during refining, 2) drying the fibres (hornification) and 3) treating the fibres with 1,2,3,4-ButaneTetraCarboxylic Acid (BTCA). If the fibres are dried (hornified), there is a lowering effect on sheet density. However, fibre curl does not have any lowering effect on sheet density. If the $\mathrm{pH}$ is decreased during plug screw treatment, the sheet density may be reduced but, again, the fibre curl does not have any positive effect on sheet density. Fibres treated with BTCA had a marked lowering effect on sheet density. With this treatment, the fibre curl does have a positive effect on sheet density. The BTCA-treated fibres were also used to lower sheet density. A mixture of $15 \%$ by weight BTCA- treated fibres resulted in an approximately $9 \%$ density reduction.

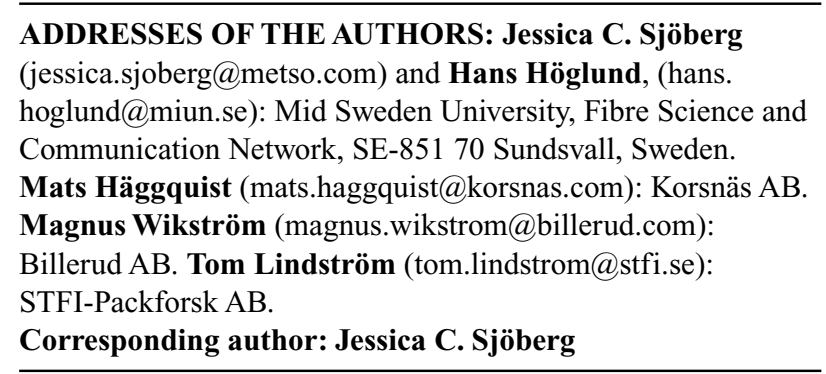

The mechanical characteristics of a paper are determined by the inherent properties of the fibres, the fibre-to-fibre bond strength and the geometrical configuration of the fibre network. Fibre parameters such as length, width and curl, as well as fibre orientation and bond strength, affect the macroscopic properties of the paper. On the macroscopic level, the density and porosity of paper characterise its physical appearance. These properties are important in many end uses of paper and board. Moreover, density and porosity indirectly characterise the three-dimensional structure (Jangmalm et al. 1995).

Density is important because it affects many other properties of paper, including tensile strength, elastic modulus and bending stiffness. These paper properties are determined not only by the density but also by how that particular density was achieved through a combination of fibre types and pigments, beating, wet pressing and calendering (Gullichsen et al. 1998). It is well known that curled fibres may result in a paper sheet with a lower density and a lower tensile index. Curlsetting by heat treatment may lower the sheet density, provided that care is taken to avoid side reactions that may affect fibre flexibility. Mechanical curlation of chemical pulps often increase sheet density because of its related increase in fibre flexibility (Page et al. 1985).

Each pulp has its own potential for bending stiffness, but the final level in paper or board is often lower than that potential because of unsuitable paper machine conditions and converting treatments. For a paper sheet with no elastic modulus gradient in the thickness direction, the bending stiffness per unit width is the product of the elastic modulus and the moment of inertia (Fellers et al. 1983).

$$
S_{b}=\frac{E I}{b}=\frac{E t^{3}}{12},
$$

Where

$\mathrm{S}_{\mathrm{b}}=$ Bending stiffness (per unit width)

$\mathrm{E}=$ Elastic modulus

$\mathrm{I}=$ Moment of inertia

$\mathrm{b}=$ Width of the test piece

$\mathrm{t}=$ Thickness

$\mathrm{w}=$ Basis weight

$\rho=$ Density

The most important paper property in this equation is evidently its density and basis weight, even if the specific elastic modulus is also important. The bending stiffness is affected by the basis weight. The following rules of thumb describe the effect of pulp: flexible fibres yield a dense paper and low bending stiffness, whereas stiff fibres, provided that there is efficient fibre-fibre bonding, yield a paper with low density and high bending stiffness (Steadman et al. 1985). Increased beating affects both bonding ability and fibre flexibility, and thus strongly raises the elastic modulus of paper. Since flexible fibres also reduce paper thickness, there may be no change in the bending stiffness under certain circumstances (Gullichsen et al. 1998). 
According to patent literature (e.g. EP 0631014 B1), sheet density can be decreased by a combination of heat treatment and gentle mechanical action. This assertion was the starting point for the investigations reported in this paper.

In order to investigate the possibility of density reduction through a combination of heat and gentle mechanical treatment, a trial was undertaken in a pilot plant equipped with a plug screw and a pressurised high consistency refiner $\left(\mathrm{HC}_{\mathrm{press}}\right.$ refiner). Earlier findings had shown that plug screw treatments, $\mathrm{HC}_{\text {press }}$ refining and use of the Bivis technique may increase fibre curl considerably and thus decrease density (Sjöberg et al. 2005, Sjöberg et al. 2007). These treatments also increased fibre flexibility to some extent. In these trials an unbleached kraft pulp with a kappa number of approximately 43 was used.

To reduce the effect of excessive fibre flexibility, three ways of improving fibre stiffness were tested in the current investigation: 1) lowering the $\mathrm{pH}$ during refining, 2) drying the fibres (hornification) and 3) treating the fibres with 1,2,3,4-ButaneTetraCarboxylic Acid (BTCA).

As mentioned earlier, the flexibility of the fibres also affects the density of the paper. One radical way of making the fibres less flexible is to treat them with BTCA. The reaction of BTCA and cellulose in the presence of a catalyst (sodium dihydrogenphosphate monohydrate - $\mathrm{NaH}_{2} \mathrm{PO}_{4}{ }^{*} \mathrm{H}_{2} \mathrm{O}$ ) proceeds in a sequential fashion, with initial incorporation of pendant BTCA residues via an anhydride-initiated esterification reaction, followed by further transformation of these newly formed branches into crosslinks of the cellulose fibres (Zhou et al. 1995). The literature on fibre crosslinking has also recently been reviewed by Lindström et al. (2005). BTCA treatment reduces the swelling of the fibre wall of unbleached kraft pulps and also the pore size distribution. The low swelling may be due to pronounced crosslinking of the fibre wall (Häggquist et al. 1998).

This paper describes attempts to lower the sheet density of unbleached kraft pulp that is to be used in the middle layer of paper board. The method is applying mechanical action by a plug screw and $\mathrm{HC}_{\text {press }}$ refining technique treatments, combined with hornification of the fibres and/or chemical treatment with BTCA to produce fibres that are both very curly and stiff.

\section{Experimental}

\section{Pulp}

All the applied pulps were commercially produced, unbleached and never-dried kraft pulp from Korsnäs AB. The pulps were manufactured from a wood mix of approximately $35 \%$ spruce and $65 \%$ pine with a kappa number of approximately 53, which corresponds to a yield of approximately $52 \%$. The pulps were collected after the HC pressing at PM 5 at Korsnäs AB. The solids content was approximately $35 \%$ and the $\mathrm{pH}$ was approximately 8 .

\section{Pressurized Refining}

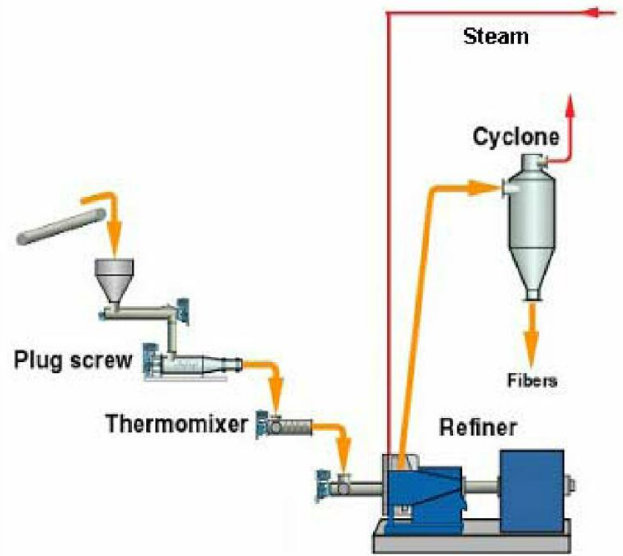

Fig 1. The operating principle of the plug screw system and the $\mathrm{HC}_{\text {press }}$ refiner.

\section{Plug screw (PREX) pre-treatment and $\mathbf{H C}_{\text {press }}$ refining}

A trial using a plug screw attached to an $\mathrm{HC}_{\text {press }}$ refiner was undertaken at the Metso Paper R\&D Centre's pilot plant in Sundsvall, Sweden. The objective was to evaluate how the treatment in a commonly used plug screw affects both fibre and paper properties, and in particular, how fibre curl affects sheet density.

At room temperature, the pulp was first fed to the plug screw at a rate of $1 \mathrm{~kg} / \mathrm{min}$ (see Fig 1). The plug screw, a conical screw with a compression ratio of $1: 4$, conveyed the pulp to a steamed atmosphere in the thermomixer. In the outflow of the plug screw, the pulp encountered compression stresses at the temperature present in the thermomixer. The temperature of the pulp increased along the plug screw, reaching its final level in the steamed and pressurised thermomixer. The dwell time in the thermomixer was 1-2 minutes. Pulp samples were treated at $100^{\circ} \mathrm{C}, 125^{\circ} \mathrm{C}$, and $175^{\circ} \mathrm{C}$, with the corresponding steam pressures in the thermomixer. Some of the samples treated at each temperature were passed through the plug screw once, while others went through it twice or three times. The procedure for samples being put through the screw treatments more than once was that, after treatment in the plug screw and the thermomixer, the pulp was blown through the refiner and immediately collected and returned to the plug screw. The refiner was set at the maximum plate gap to minimise mechanical treatment of the fibres. The refiner was equipped with 20 -inch segments of type 5811S, manufactured by Metso Paper, and the rotation speed of the disc was $1500 \mathrm{rpm}$.

In another trial, pulp samples were $\mathrm{HC}_{\text {atm }}$ refined at $100^{\circ} \mathrm{C}$, and $\mathrm{HC}_{\text {press }}$ refined at $125^{\circ} \mathrm{C}$ and $175^{\circ} \mathrm{C}$.

The effect of lowering the $\mathrm{pH}$ in the pulp during plug screw treatment was also investigated in order to see whether a lower degree of swelling of the fibre wall would contribute to the fibre stiffness and thus a lower sheet density.

\section{pH treatment and drying (hornification)}

In order to lower the $\mathrm{pH}$ in the pulp, it was diluted to approximately $4.5 \%$ pulp consistency, after which 
sulphuric acid was added until a $\mathrm{pH}$ of approximately 5 was reached. The pulp was then dewatered in a twin-roll press to approximately $35 \%$ pulp consistency and fed to the plug screw and treated at $45^{\circ} \mathrm{C}$ and $175^{\circ} \mathrm{C}$ in the thermomixer. Pulp samples with two different $\mathrm{pH}$-values, $\mathrm{pH} 5$ and $\mathrm{pH} 8$, were treated in the plug screw twice. Thereafter, a few pulp samples were dried in an oven at approximately $100^{\circ} \mathrm{C}$ in order to investigate the effect of hornification on fibre stiffness and sheet density.

\section{1,2,3,4-ButaneTetraCarboxylic Acid (BTCA) treatment}

The procedure for the BTCA treatment of curled fibres was similar to that set out in Häggquist et al. (1998). The objective was to lower fibre swelling caused by pronounced crosslinking of the fibre wall, and thus obtain higher fibre stiffness and a lower sheet density. Pulp that had been treated in the plug screw was defibrated in water at room temperature according to the SCAN-C 18:65 method, and was then $\mathrm{pH}$ adjusted with $\mathrm{HCl}$ to 2.8 during stirring at approximately $1.5 \%$ consistency. The pulp was then dewatered on a Büchner funnel to approximately $20 \%$ consistency. A batch of $300 \mathrm{ml}$ solution of $2 \%$ by weight of BTCA and sodium dihydrogenphosphate monohydrate, $\left(\mathrm{NaH}_{2} \mathrm{PO}_{4}{ }^{*} \mathrm{H}_{2} \mathrm{O}\right)$ was prepared. The BTCA solution was poured onto the dewatered pulp in a container and kept there for 20 minutes. The pulp was then dewatered once more on a Büchner funnel to approximately $20 \%$ consistency. After that, the pulp was cured in an oven, with the temperature raised from $110^{\circ} \mathrm{C}$ to $150^{\circ} \mathrm{C}$ for approximately 45 minutes and then lowered to $110^{\circ} \mathrm{C}$. The pulp remained in the oven until it was fully dried. The BTCA-treated pulp was disintegrated and mixed with untreated pulp in various quantities in order to investigate its effect on sheet density. The percentage weight of BTCA-treated pulp in the mixture with untreated pulp was $5,10,15$ and $100 \%$.

\section{Fibre and pulp analyses}

An optical fibre analyser, FiberMaster (Karlsson et al. 1999), was used to determine the length-weighted average fibre length and shape factor of non-dried pulp samples. Before being analysed, the pulp was defibrated in water at room temperature according to the SCAN-C 18:65 method. The results for each sample were based on data from approximately 10000 fibres. Fibres are defined as particles with a length/width ratio greater than 4. The shape factor is defined as the projected fibre length divided by the true fibre length, so that a completely straight fibre has a shape factor of $100 \%$. The water retention value was determined in accordance with SCAN-C 62:00.

\section{Sheet properties}

Sheets were made according to the ISO-M 5:67 method and the physical properties of the paper were tested according to SCAN-P 67:93. The sheet properties presented in this paper were found within the confidence limits due to the methods.

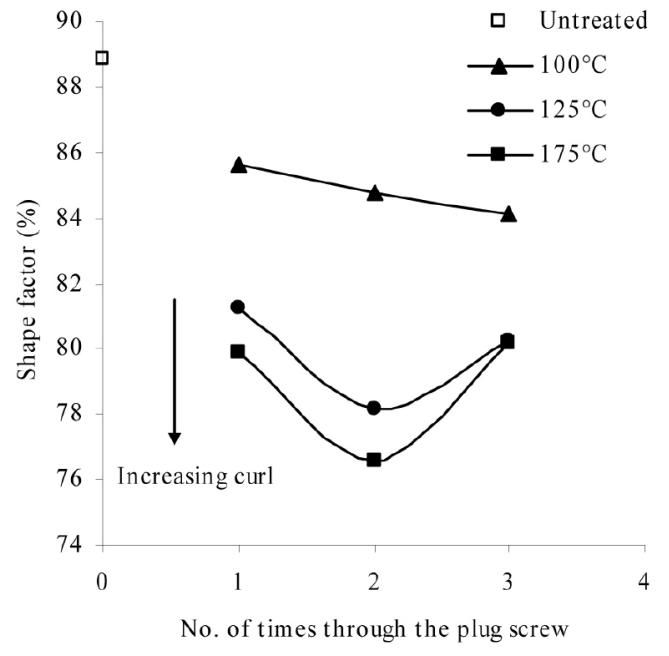

Fig 2. Average shape factor versus treatment after one to three passes through a plug screw at different temperatures.

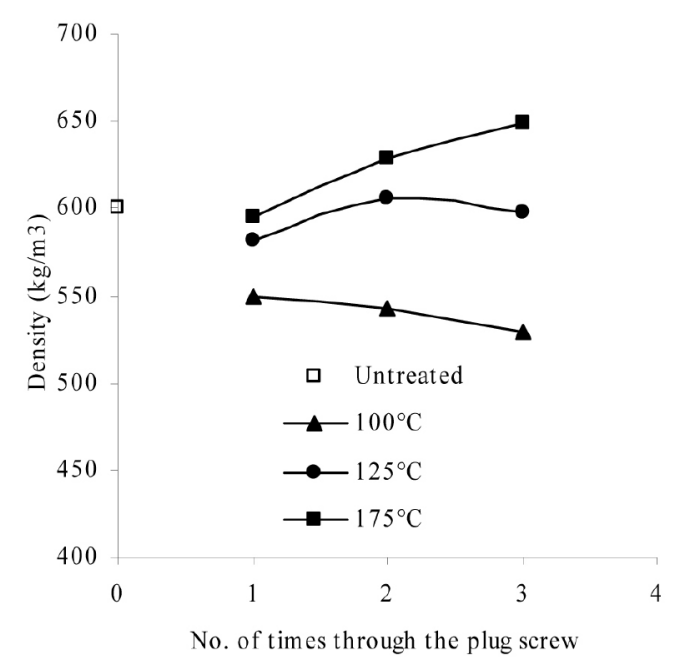

Fig 3. Density versus treatment after one to three passes through a plug screw at different temperatures.

\section{Results and Discusson}

\section{Plug screw treatment}

The length-weighted shape factor of the kraft pulp fibres decreased with the number of treatments in the plug screw at $100^{\circ} \mathrm{C}$, in other words, their curl increased (see Fig 2). For pulp treated at $125^{\circ} \mathrm{C}$ and $175^{\circ} \mathrm{C}$, the shape factor decreased after the first and second plug screw treatments, but then increased again. Sjöberg and Höglund (2005) observed a similar phenomenon after $\mathrm{HC}_{\text {press }}$ refining of pre-treated fibres in the same temperature range as in the current study. Their proposed explanation was that before $\mathrm{HC}_{\text {press }}$ refining the fibres were already curled during kneading in the plug screw in the inlet to the pre-heater. The fibres were then straightened out during the $\mathrm{HC}_{\text {press }}$ refining. Most of the curled fibres in the current study were obtained from pulp treated twice in the plug screw at $175^{\circ} \mathrm{C}$. These curled fibres were obtained with very low energy input during the plug screw treatment, $10-20 \mathrm{kWh} /$ ton. With such low energy input, it would be expected that fibre flexibility would not be greatly affected. However, in spite of the 


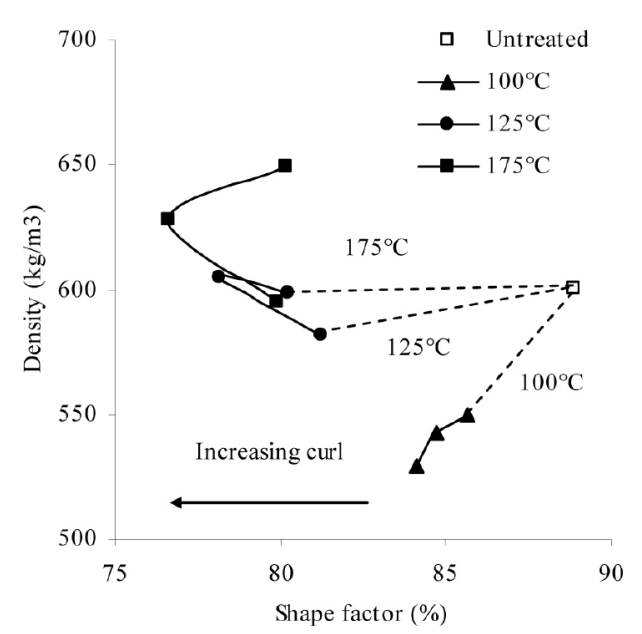

Fig 4. Density versus shape factor after one to three passes through a plug screw at different temperatures.

very low shape factor, there was only a slight decrease in sheet density after one treatment in the plug screw at $125^{\circ} \mathrm{C}$ and $175^{\circ} \mathrm{C}$ (see Fig 3). Pulp treated in the plug screw, and in particular pulp that went through the plug screw only once at $100^{\circ} \mathrm{C}$, increased its curl the least, but showed the largest decrease in density. If the pulp was fed though the plug screw again at $100^{\circ} \mathrm{C}$, the density continued to decrease slightly. But the density started to increase for pulp treated at $125^{\circ} \mathrm{C}$ and $175^{\circ} \mathrm{C}$, even though these fibres were more curled.

As mentioned earlier, the use of curled fibres is expected to result in lower sheet density. However, Fig 4 shows the opposite trend for fibres treated under steam-pressurised conditions, even though the fibre curl was achieved with very mild mechanical treatment in the plug screw. The sheet density decreased with a decreasing shape factor (increased curl) at atmospheric conditions, but a higher temperature during plug screw treatment resulted in a higher sheet density. This surprising finding indicates that during treatment under pressurised conditions in a plug screw, the fibres not only curl but probably also lose much of their stiffness and become too flexible, resulting in higher sheet density. A possible explanation for this behaviour may be that the higher pressure compresses the plug in the outlet, making it harder, while the higher temperatures soften the fibres. Fig 5 shows the relationship between the sheet density and the change in pulp consistency during plug screw treatment. The figure indicates that the more the consistency increases during the plug screw treatment, the lower the sheet density obtained. The diagram also shows that the highest increase in pulp consistency was achieved with plug screw treatment at $100^{\circ} \mathrm{C}$. It should be noted that pulp treated under pressurised conditions at $125^{\circ} \mathrm{C}$ and $175^{\circ} \mathrm{C}$ did not have as high a pulp consistency as pulp treated at $100^{\circ} \mathrm{C}$.

\section{$\mathbf{H C}_{\text {atm }}$ refining and $\mathbf{H C}_{\text {press }}$ refining}

The effects of $\mathrm{HC}_{\mathrm{atm}}$ and $\mathrm{HC}_{\text {press }}$ refining on fibre shape and paper density were evaluated using the systems shown in Fig 1. Before the treatment in the HC refiner, the pulp passed through the plug screw and the thermo-

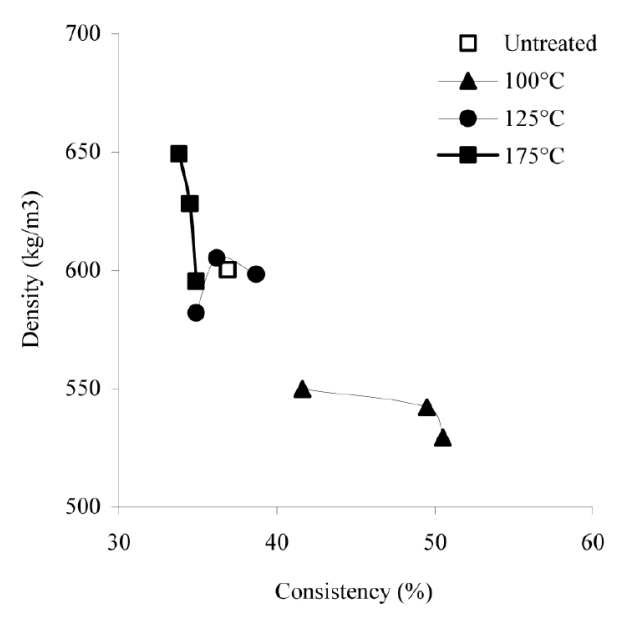

Fig 5. Density versus pulp consistency during treatment one to three passes through a plug screw at different temperatures.

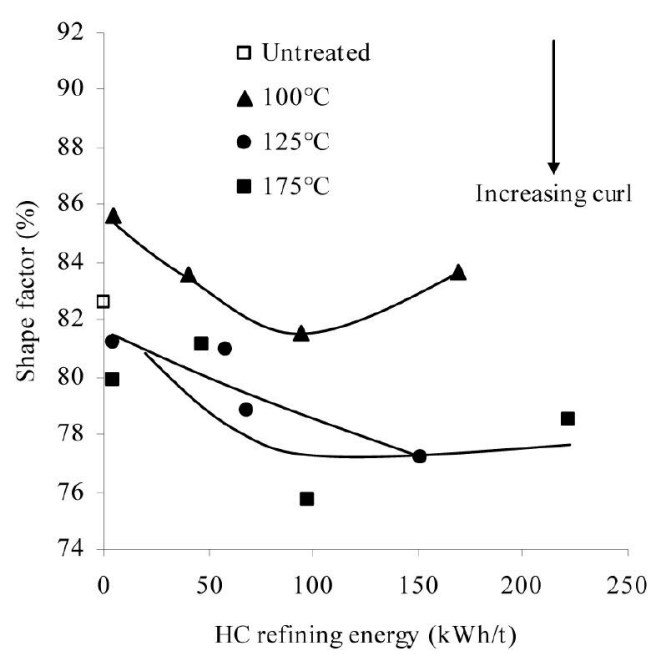

Fig 6. Shape factor versus refining energy during $\mathrm{HC}_{\text {atm }}$ refining and $\mathrm{HC}_{\text {press }}$ refining at different temperatures.

mixer once. The length-weighted shape factor dropped after refining at a low refining energy (see Fig 6). The shape factor then started to increase. This phenomenon was also noted in an earlier study of $\mathrm{HC}_{\text {press }}$ refining (Sjöberg et al. 2005). The largest amounts of curled fibres were found after $\mathrm{HC}_{\text {press }}$ refining at $175^{\circ} \mathrm{C}$ and approximately $100 \mathrm{kWh} / \mathrm{t}$.

The sheet density increased with increasing $\mathrm{HC}$ refining energy for all temperatures, $100^{\circ} \mathrm{C}, 125^{\circ} \mathrm{C}$ and $175^{\circ} \mathrm{C}$ (see Fig 7). This diagram also shows the results from pulp treated in the plug screw at approximately 5 $\mathrm{kWh} / \mathrm{t}$. It is clear that increased energy consumption in the $\mathrm{HC}$ refining increases the sheet density, despite the increased fibre curl. It is also obvious that a loss of fibre stiffness occurs during $\mathrm{HC}_{\text {atm }}$ and $\mathrm{HC}_{\text {press }}$ refining. The increased fibre flexibility has a higher impact on the density of the final product than the shape factor of the fibres. Fibre flexibility does not seem to increase as much during refining at the highest temperature $\left(175^{\circ} \mathrm{C}\right)$ as it does at lower temperatures.

Fig 8 shows how the sheet density is dependent on the pulp consistency during $\mathrm{HC}_{\mathrm{atm}}$ and $\mathrm{HC}_{\text {press }}$ refining. In the plug screw treatment (see Fig 5), it was found that the 


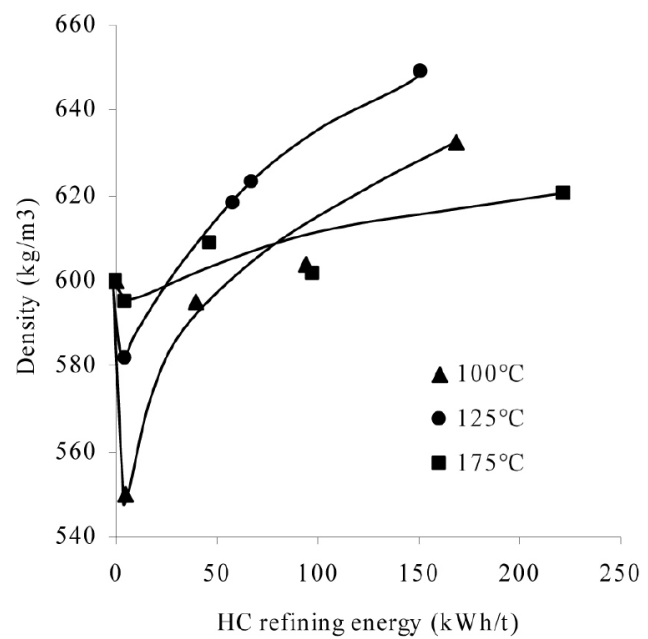

Fig 7. Density versus refining energy during $\mathrm{HC}_{\text {atm }}$ refining and $\mathrm{HC}_{\text {press }}$ refining at different temperatures.

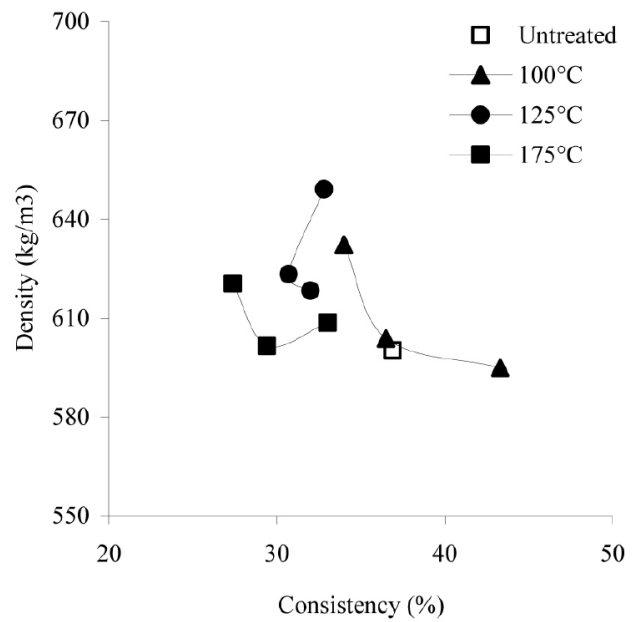

Fig 8. Density versus pulp consistency during $\mathrm{HC}_{\text {atm }}$ refining and $\mathrm{HC}_{\text {press }}$ refining at different temperatures.

sheet density has a tendency to decrease with increasing consistency. However, the change in sheet density does not reveal any significant correlation with the change in consistency during $\mathrm{HC}_{\text {atm }}$ and $\mathrm{HC}_{\text {press }}$ refining, even if a trend is indicated for $\mathrm{HC}_{\text {atm }}$ refining. A comparison of Figs 6 and 7 shows that there is no correlation between fibre curl and paper density. The explanation for this finding is probably that the fibres that become most curled also become too flexible, leading to densification of the paper sheet.

\section{The effect by pH during plug screw treatment and the subsequent hornification}

Even though fibre curl increased considerably during plug screw treatment and $\mathrm{HC}_{\text {atm }}$ and $\mathrm{HC}_{\text {press }}$ refining, the sheet density of the paper sheets was not lowered as had been expected. When this became obvious, different ways of stiffening the curled fibres were investigated. These trials were performed on another batch of pulp.

The effect of $\mathrm{pH}$ was first considered. It is well known that a higher $\mathrm{pH}$ has a beneficial effect on fibre swelling. A lower $\mathrm{pH}$ leads to reduced swelling (Lindström et al. 1982a) and enhanced hornification when the fibres are dried (Lindström et al. 1982b). The $\mathrm{pH}$ of the pulp does not

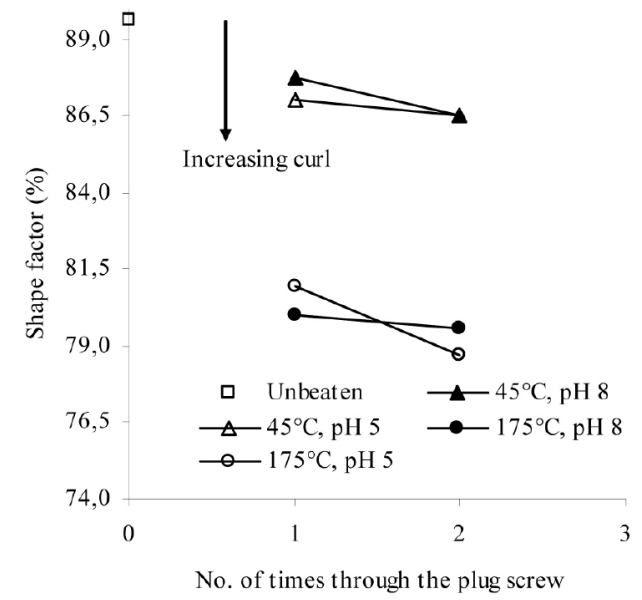

Fig 9. Shape factor versus treatment for one and two passes through a plug screw at different temperatures and $\mathrm{pH}$.

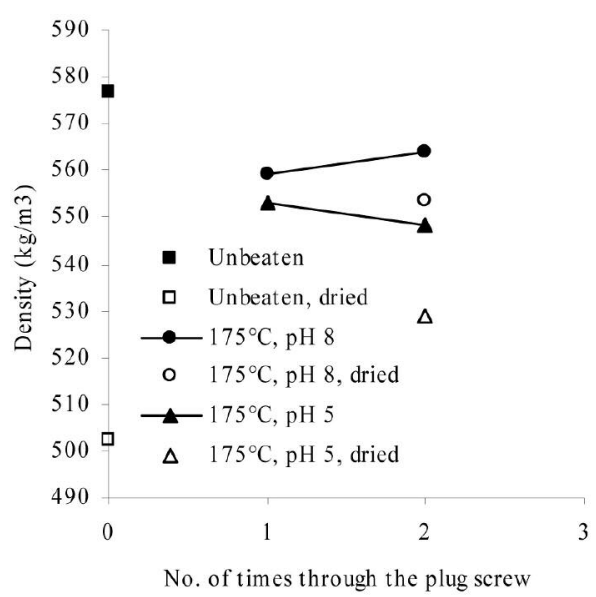

Fig 10. Density versus treatment for one and two passes through a plug screw at $175^{\circ} \mathrm{C}$ and for different $\mathrm{pH}$ of dried and undried pulp.

influence the shape factor during plug screw treatment (see Fig 9), but the temperature during plug screw treatment has a significant influence, as shown earlier. The higher the temperature, the larger the curl increase. Fig 10 indicates that a lower $\mathrm{pH}$ during plug screw treatment results in a somewhat lower sheet density. This can be explained by the fact that at a lower $\mathrm{pH}$, fibres are less swollen and are thus stiffer, resulting in a lower sheet density.

Another well known way to make a fibre wall stiffer is to use the effect of hornification during drying. Hornification of fibres is associated with a reduction in their swelling ability. The properties of the formed network are also affected. It has, for example, been shown that recycling of chemical fibres results in a paper with lower strength properties and lower density (Howard et al. 1992). In this case, hornification of the fibres also leads to a decrease in sheet density for unbeaten pulp and pulp plug-screwed at $175^{\circ} \mathrm{C}$ (see Fig 10). The most significant decrease in density due to hornification appears in the unbeaten pulp.

\section{Effect of BTCA treatment}

In this investigation, the BTCA treatment was the most drastic method of increasing the fibre stiffness of the cur- 


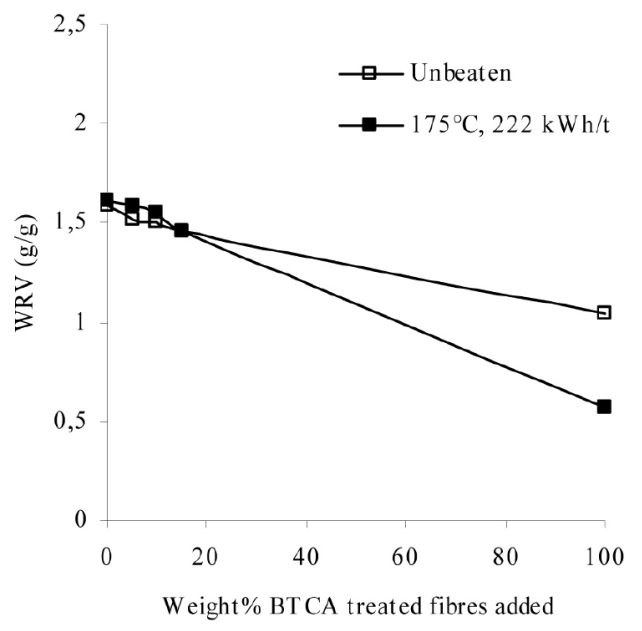

Figure 11. Water retention value versus weight \% BTCA-treated fibres added to untreated fibres.

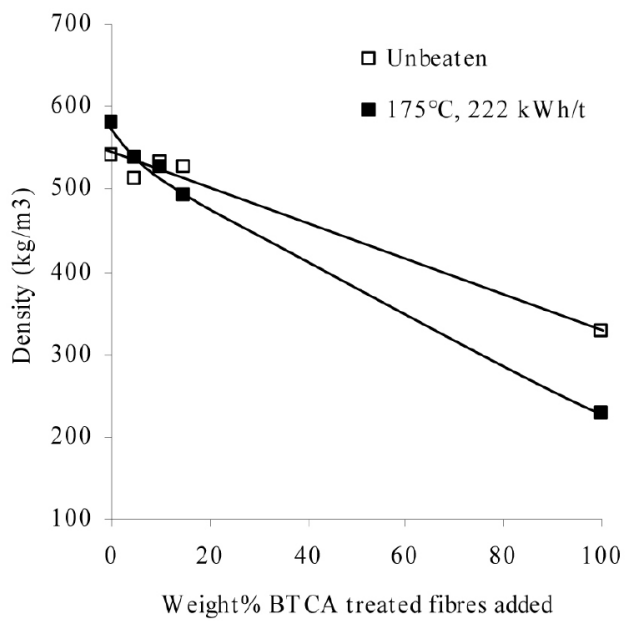

Fig 12. Density versus weight \% BTCA-treated fibres added to untreated fibres.

led fibres. BTCA treatment results in reduced swelling of the fibre wall of both unbeaten unbleached kraft pulp and the curly $\mathrm{HC}_{\text {press }}$ refined pulp (see Fig 11). The low swelling is due to pronounced crosslinking of the fibre wall (Häggquist et al. 1998). The BTCA treatment also results in a significant decrease in sheet density (see Fig 12). The explanation of this behaviour is most likely that the crosslinking makes the fibres less flexible. It is also interesting that the most curled fibres, the pulp $\mathrm{HC}_{\text {press }}$ refined at $175^{\circ} \mathrm{C}$ and $222 \mathrm{kWh} / \mathrm{t}$, revealed the lowest density after the BTCA treatment. The shape factor was measured for both pulps before and after BTCA treatment but showed no significant change due to the treatment. Shape factor for unbeaten pulp was approximately 87.5 and $\mathrm{HC}_{\text {press }}$ refined pulp at $175^{\circ} \mathrm{C}$ and $222 \mathrm{kWh} / \mathrm{t}$ was approximately $78.2 \%$. In the untreated stage, curled fibres have the highest sheet density. It is evident that the fibre stiffness needs to be increased considerably to take advantage of the contribution of curly fibres to sheet density.

\section{Conclusions}

Kraft pulp fibres were treated in a compressive plug screw and in a $\mathrm{HC}$ refining stage to increase fibre curl. The shape factor of the fibres was reduced and curl incre- ased with the number of treatments in the plug screw at $100^{\circ} \mathrm{C}$. For pulp treated at $125^{\circ} \mathrm{C}$ and $175^{\circ} \mathrm{C}$, the shape factor decreased after one and two passes through a plug screw, but then increased again. However, in spite of the very low shape factor of the fibres, the sheet density decreased only slightly after one treatment in the plug screw at $100^{\circ} \mathrm{C}, 125^{\circ} \mathrm{C}$ and $175^{\circ} \mathrm{C}$. When the pulp was further treated at $100^{\circ} \mathrm{C}$ in the plug screw, the density continued to decrease, but it started to increase for pulp treated at $125^{\circ} \mathrm{C}$ and $175^{\circ}$.

Pressurised $\mathrm{HC}$ refining, on the other hand, showed no lowering effects on sheet density.

Even though the fibres were very curled, there was no significant decrease in the sheet density of papers made from this pulp. To achieve a lowering effect of sheet density, some kind of chemical or structural treatment appears necessary. If the fibres are dried (hornified), there is a lowering effect on sheet density, but the fibre curl does not have a positive effect on sheet density. If the $\mathrm{pH}$ is decreased during plug screw treatment, sheet density can be decreased, but, again, the fibre curl makes no positive contribution to sheet density. When the fibres are treated with BTCA, the WRV drops dramatically. It is suggested that the fibres are crosslinked, and are thus less flexible. The results show that a combination of curled and stiff fibres result in a decreased sheet density. With cross-linking, fibre curl also has a positive effect on sheet density. The BTCA-treated fibres were also used to decrease sheet density and resulted in an approximately $9 \%$ decreased density with a mixture of $15 \%$ BTCA-treated fibres by weight.

\section{Acknowledgements}

The authors would like to thank Korsnäs $A B$ for their economic support, for supplying kraft pulp, and for their valuable knowledge of the production of paperboard. The authors would also like to thank Metso R\&D Centre in Sweden for their assistance and Proper English AB for linguistic revision.

\section{Literature}

European patent specification (1997): EP 0631014 B1, Soft tissue product and process of making same. Proprietor: Kimberly-Clark Corporation 1997. Representative: Diehl, Hermann.

Fellers, C., de Ruvo, A., Htun, M., Carlsson, L., Engman, C. and Lundberg, R. (1983): Carton Board, Profitable use of pulps and processes, p 55, STFI, Stockholm, Sweden.

Gullichsen, J. and Paulapuro, H. (1998): FAPET - Papermaking Part 16, Paper Physics End, Published in cooperation with the Finnish Paper Engineers' Association and TAPPI.

Gullichsen, J. and Paulapuro, H, (1998): Papermaking Science and Technology, Book 16, Paper Physics, Jyväskylä 1998, Fapet Oy.

Howard, R.C. and Bichard, W. (1992): The basic effects of recycling on pulp properties, J. Pulp Paper Sci.18(4), 151.

Häggquist, M., Solberg, D., Wågberg, L. and Ödberg L. (1998): The influence of two wet strength agents on pore size and swelling of pulp fibres and on tensile strength properties, Nord. Pulp Paper Res. J. 13 (4), 292-298.

Jangmalm, A. and Östlund, S. (1995): Modelling of curled fibres in two-dimensional networks, Nord. Pulp Paper Res. J. Vol (3), 156-166.

Karlsson, H., Fransson P-I. and Mohlin, U-B. (1999): STFI FIBERMASTER, SPCI 6th International Conference on New Available Technologies, June 3, Stockholm. 
Lindström, T. and Kolman, M. (1982a): The effect of pH and electrolyte concentration during beating and sheet forming on paper strength, Svensk Papperstidning, 85(15), R140.

Lindström, T. and Carlsson, G. (1982b): The Effect of Carboxyl Groups and their Ionic Form during Drying on the Hornification of Cellulose Fibers, Svensk Papperstidning, 85(15), R146.

Lindström T, Wågberg L and Larsson T (2005): On the nature of joint strength in paper $-A$ review of dry and wet strength resins in paper manufacturing, 13th Fundamental Res. Symp. held in Cambridge, Sept 2005, "Advances in paper science and technology", The Pulp \& Paper Fundamental Res. Society, 1, 457-562.

Page, D.H., Seth, R.S., Jordan, B.D. and Barbe, M.C. (1985): Curl, crimps, kinks and microcompressions in pulp fibres - their origin, measurement and significance, Papermaking Rawmaterials, 8th Fundamental Research Symposium, Mech. Eng. Publ. Ltd., London, 183-227.
Sjöberg, J. C. and Höglund, H. (2005): Refining systems for sack paper pulp: Part I. HC refining under pressurised conditions and subsequent LC refining, Nord. Pulp Paper Res. J. 20 (3), 320-328.

Sjöberg, J.C. and Höglund, H. (2007): Refining systems for sack paper pulp: Part II. Plug screw and Bivis treatment under pressurised conditions and subsequent LC refining, Nord. Pulp Paper Res. J. 22 (1), 61-71.

Steadman, R. and Luner, P. (1985): The effects of wet fibre flexibility of sheet apparent density, Papermaking Rawmaterials, 8th Fundamental Research Symposium, Mech. Eng. Publ. Ltd., London, 311-337.

Zhou, Y.J., Luner, P. and Caluwe, P. (1995): Mechanism of cross-linking of papers with polyfunctional carboxylic acids, J. Appl. Polym. Sci. 58: 1523-1534.

Manuscript received April 19, 2007 Accepted November 16, 2007 